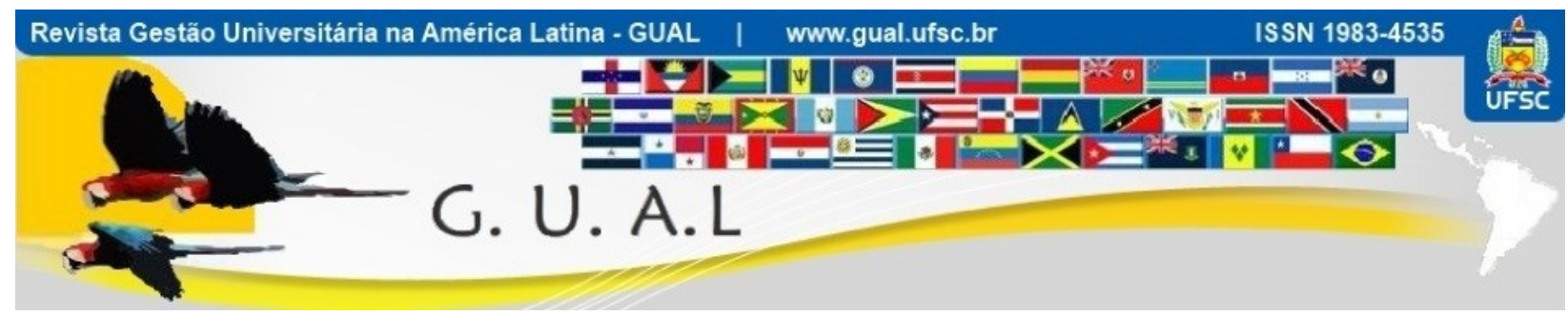

DOI: http://dx.doi.org/10.5007/1983-4535.2013v6n3p269

\title{
CONTRIBUIÇÕES DO PDI E DO PLANEJAMENTO ESTRATÉGICO NA GESTÃO DE UNIVERSIDADES FEDERAIS
}

\section{CONTRIBUTIONS OF PDI AND STRATEGIC PLANNING IN THE MANAGEMENT OF FEDERAL UNIVERSITIES}

Júlio Eduardo Ornelas Silva, Doutorando

Universidade Federal de Santa Catarina - UFSC julioornelas@yahoo.com.br

Pedro Antônio de Melo, Doutor Universidade Federal de Santa Catarina - UFSC pedro.inpeau@gmail.com

Alexandre Moraes Ramos, Doutor Universidade Federal de Santa Catarina - UFSC amrrms@,gmail.com

Cláudio José Amante, Doutor Universidade Federal de Santa Catarina - UFSC claudiojosea@yahoo.com.br

Flora Moritz da Silva, Doutoranda Universidade Federal de Santa Catarina - UFSC

floramds@gmail.com

\section{ESTA PESQUISA RECEBEU APOIO E FINANCIAMENTO DA CAPES/OBEDUC}

Recebido em 18/março/2013

Aprovado em 11/junho/2013

Sistema de Avaliação: Double Blind Review

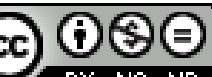

Esta obra está sob uma Licença Creative Commons Atribuição-Uso. 


\title{
RESUMO
}

Este artigo pretendeu analisar as contribuições do Plano de Desenvolvimento Institucional e do Planejamento Estratégico na gestão de universidades federais brasileiras, no qual foram realizadas análises documentais e entrevistas in loco em oito universidades federais, sendo a UFAL, a UFGD, a UFMA, a UFMG, a UFPA, a UFSC, a UnB e a UNIFAP. As características das universidades estudadas são peculiares, no entanto, a experiência dos gestores entrevistados evidenciou que tanto o PDI quanto o planejamento estratégico trazem contribuições para a gestão das universidades, ao possibilitar o autoconhecimento, o delineamento de metas, objetivos e estratégias, propiciando um rumo às universidades $\mathrm{e}$, em alguns casos, trilhando o futuro com uma visão competitiva.

Palavras-chave: PDI. Planejamento Estratégico. Universidades Federais. Gestão Universitária.

\begin{abstract}
This article aims to analyze the contributions of the Institutional Development Plan and Strategic Planning in the management of Brazilian Federal Universities, which carried out interviews and documentary analysis in eight federal universities: UFAL, UFGD, UFMA, UFMG, UFPA, UFSC, UNB and UNIFAP. The characteristics of the universities studied are unique, however, the experience of managers interviewed evinces that the PDI and strategic planning bring contributions to the management of universities, to enable the self, the delineation of goals, objectives and strategies, providing a course universities and, in some cases, treading the future with a competitive vision.
\end{abstract}

Keywords: PDI. Strategic Planning. Federal Universities. Management University. 


\section{INTRODUÇÃO}

Pesquisas que visem contribuir para que as universidades melhorem suas gestões, acabam por contribuir também para que elas alcancem seus objetivos, que é a geração de conhecimentos, o que consequentemente trazem desenvolvimento para a sociedade em que se inserem. Muriel (2006) e Machado (2008) acreditam que um bom planejamento pode trazer melhorias significativas à gestão de uma instituição de educação superior, potencializando as contribuições dessas organizações para a sociedade.

As universidades, como os demais órgãos públicos brasileiros, historicamente não estão habituados com a atividade de planejamento, sendo setores sensíveis a políticas de governos e situação dos mercados. Os gestores dos órgãos públicos viviam para "apagar incêndios" e decidir a melhor maneira de utilizar um recurso escasso, caso viesse. Amaral (2003) demonstra essas dificuldades financeiras quando evidencia que os recursos destinados às universidades pelo governo federal de 1989 a 2011 caíram, obrigando seus gestores a adaptações internas que nem sempre eram positivas para as instituições.

Silva et al (2011) mostra que essa situação começou a mudar a partir de 2003, quando a economia mundial prosperou e consequentemente, a brasileira. Soma-se também uma mudança de postura do governo federal para com as universidades federais, quando houve troca do presidente da república, acarretando em um aumento considerável dos recursos federais destinados a essas instituições. Essa fase coincide com o início das ações referente ao planejamento nas universidades, quando, por força de lei de 2004 (BRASIL, 2004), elas foram obrigadas a elaborarem um documento de planejamento, denominado Plano de Desenvolvimento Institucional - PDI.

É nesse cenário que o presente artigo se insere, em apresentar à academia conhecimentos que contribuam para o aperfeiçoamento da gestão de universidades federais brasileiras, apontando as contribuições do PDI e do Planejamento Estratégico para as gestões das universidades federais brasileiras. Para se chegar as conclusões, foram levantados dados e realizadas entrevistas em oito universidades federais brasileiras, sendo as Universidade Federal de Alagoas, Universidade Federal do Amapá, Universidade Federal da Grande Dourados, Universidade Federal do Maranhão, Universidade Federal de Minas Gerais, Universidade de Brasília, Universidade Federal do Pará e Universidade Federal de Santa Catarina. 


\section{FUNDAMENTAÇÃO TEÓRICA}

Nesta seção são apresentados os fundamentos teóricos que subsidiam a condução da pesquisa, fornecendo conhecimentos necessários para melhor aprofundamento dos temas. Dessa forma, são tratadas as temáticas Estratégia, Planejamento estratégico e Plano de Desenvolvimento Institucional.

\subsection{PLANEJAMENTO ESTRATÉGICO}

Segundo Pereira (2010), o planejamento teve seu início formal quando Taylor sugeriu que se utilizasse métodos científicos na administração de organizações, estabelecendo previamente medidas a serem seguidas. Maximiano (2012) acrescenta que Taylor (18561915) contribuiu para o início do movimento da administração científica, contemporaneamente ao surgimento da escola clássica de administração, cujo personagem mais importante foi Henry Fayol (1841-1925).

Maximiano (2012, p. 51) esclarece que Fayol teorizou sobre planejamento quando criou as seis atividades ou funções distintas de uma empresa, sendo (1) a função comercial: compra, venda e troca; (2) a função financeira: procura e utilização de capital; (3) a função de administração: planejamento, organização, comando, coordenação e controle; (4) a função de segurança: proteção da propriedade e das pessoas; (5) a função de contabilidade: registro de estoques, balanços, custos e estatística; e (6) a função técnica: produção e manufatura. Essas funções e a localização do planejamento em seu contexto podem ser melhor observadas na ilustração 1 .

Ilustração 1 Funções da empresa, segundo Fayol

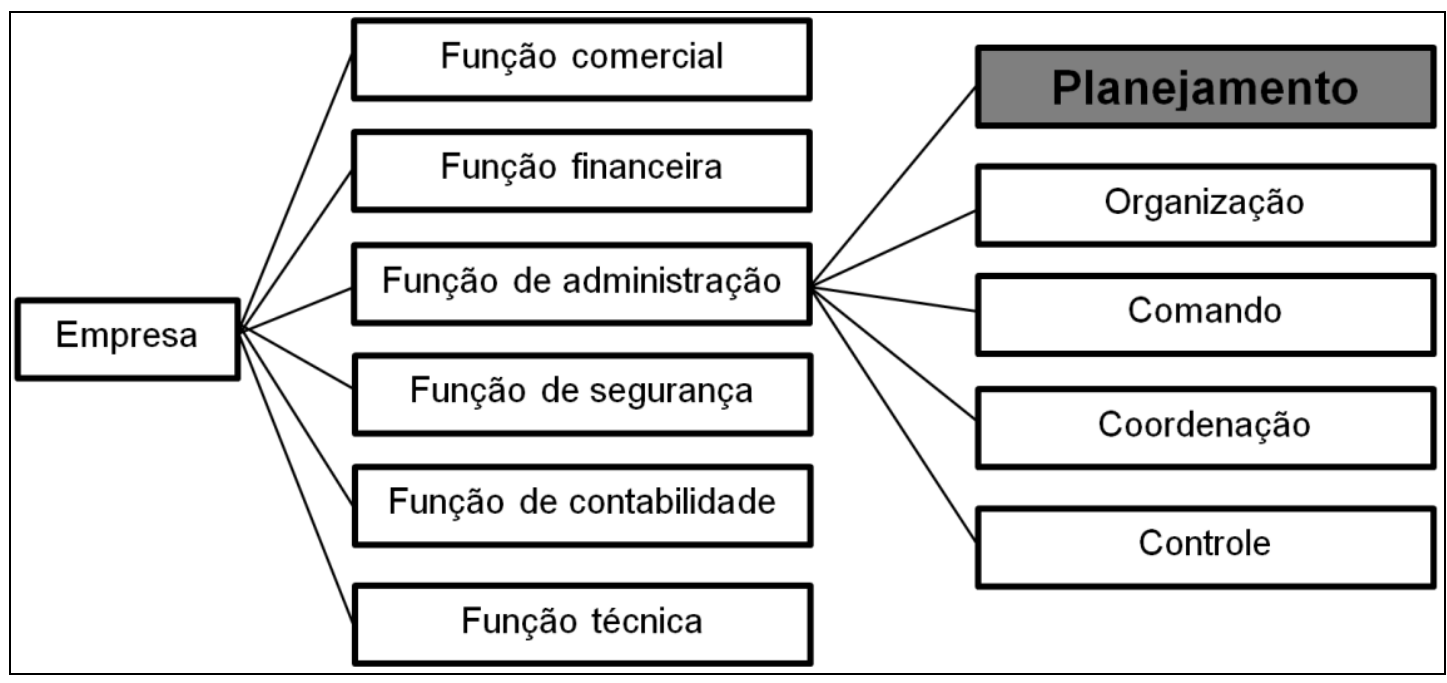

Fonte: Maximiano (2012, p. 50). 
De todas as funções da empresa, Maximiano (2012) explica que a função administrativa era a mais importante para Fayol, podendo também ser dividida em planejar, organizar, executar, liderar e controlar. É nesse contexto que aparece a ideia de planejamento.

A atividade de planejamento naturalmente origina decisões presentes tomadas a partir do exame do impacto das mesmas no futuro, dando-lhe o que Oliveira (2008) chama de dimensão temporal de alto significado. A busca é pela redução da incerteza envolvida no processo decisório, e consequentemente, uma maior probabilidade de alcance dos objetivos, metas e desafios delineados pela organização. Dessa forma, segundo o autor, o processo de planejar gera indagações que "[...] envolvem questionamentos sobre o que fazer, como, quando, quanto, para quem, por que, por quem e onde." (2008, p. 5).

Três tipos de planejamento são apresentados por Oliveira (2008), considerando os níveis hierárquicos e de decisão de uma empresa, conforme ilustração 2.

Ilustração 2 Níveis de decisão e tipos de planejamento

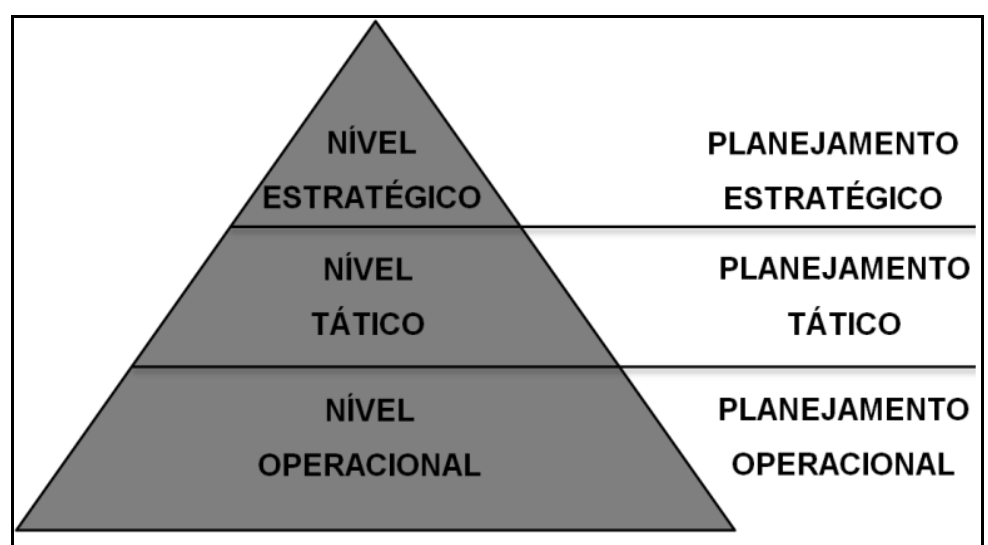

Fonte: Oliveira (2008, p. 15).

É nesse raciocínio que aparece o planejamento estratégico, que segundo Pereira (2010), está vinculado ao nível de decisão mais alto da organização. Para o nível médio, cabem os planejamentos táticos, e para o nível operacional, cabem os planos operacionais.

Costa (2012) traz contribuições ao classificar a mentalidade dos dirigentes em relação ao futuro de três maneiras, sendo a mentalidade imediatista, a operacional e a estratégica. A mentalidade imediatista visualiza o que irá ocorrer no espaço de um mês e apenas aquilo que se passa dentro da organização. A mentalidade operacional baseia-se em fatos do cotidiano e em demandas para que tudo ocorra normalmente, e o espaço temporal é de doze meses. A mentalidade estratégica possui visão do futuro, em um espaço de cinco a dez anos e sob uma perspectiva global. A ilustração 3 evidencia essas contribuições do autor. 
Ilustração 3 Mentalidade imediatista, operacional e estratégica

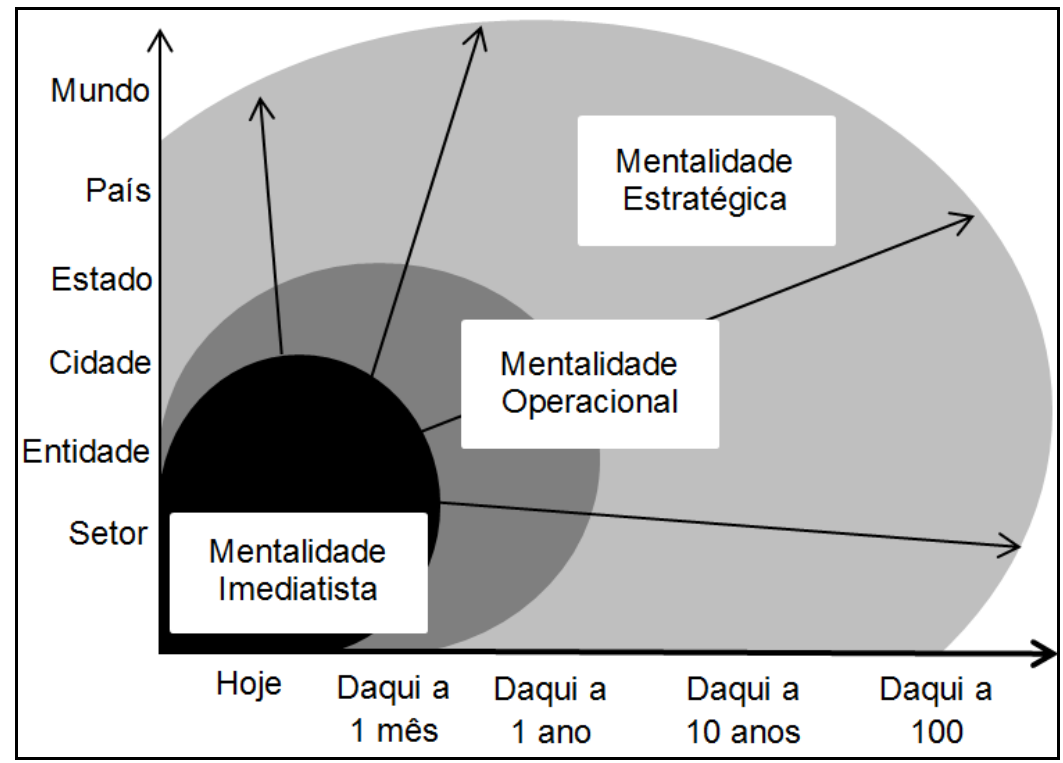

Fonte: Costa (2012, p. 15).

No conceito de Almeida (2010, p. 5), "planejamento estratégico é uma técnica administrativa que procura ordenar as ideias das pessoas, de forma que se possa criar uma visão do caminho que se deve seguir (estratégia).”. Após a ordenação das ideias, organiza-se as ações, implementando o plano estratégico para que se caminhe na direção pretendida, sem desperdício de esforços. Na concepção de Pereira (2010, p. 47), planejamento estratégico é um processo que consiste na análise sistemática dos pontos fortes (competências) e fracos (incompetências ou possibilidades de melhorias) da organização, e das oportunidades e ameaças do ambiente externo, com o objetivo de formular (formar) estratégias e ações estratégicas com o intuito de aumentar a competitividade e seu grau de resolutividade.

Complementando, Oliveira (2008, p. 4) entende que o "planejamento estratégico corresponde ao estabelecimento de um conjunto de providências a serem tomadas pelo executivo para uma situação em que o futuro tende a ser diferente do passado.”. Para Almeida (2010), o planejamento estratégico não indica como administrar o dia a dia do trabalho, mas mostra como estruturar ações, ajudando os gestores a organizarem suas ideias e direcionar suas ações.

\subsection{PLANO DE DESENVOLVIMENTO INSTITUCIONAL}

O Plano de Desenvolvimento Institucional - PDI existente no Brasil pode ser considerado uma novidade, que só veio ser praticado a partir da segunda metade da década 
dos anos 2000. Suas origens estão na Lei de Diretrizes e Bases da Educação - LDB (BRASIL, 1996), que institui em seu artigo nono a necessidade de avaliação da educação superior pela União.

De modo a detalhar as ações da avaliação, regulamentando o referido artigo da LDB, foi aprovado a Lei Federal n ${ }^{\circ}$ 10.861, em 2004, que institui o Sistema Nacional de Avalição da Educação Superior - SINAES (BRASIL, 2004). Em seu escopo, o SINAES busca melhorar a qualidade da educação superior brasileira por meio da avaliação das instituições de educação superior, cursos de graduação e desempenho acadêmico.

É nesse contexto que surge o PDI, quando o SINAES (BRASIL, 2004) torna obrigatória a prática do Plano de Desenvolvimento Institucional para que as instituições de educação superior possam ser avaliadas em qualquer etapa de suas existências. O detalhamento mínimo do que deve constar no PDI foi discriminado pelo decreto presidencial $\mathrm{n}^{\mathrm{o}}$ 5.773, de 2006 (BRASIL, 2006). Elaborado para um período de cinco anos, o PDI é definido pelo MEC (BRASIL, 2007, s/p) como um

[...] documento que identifica a Instituição de Ensino Superior (IES), no que diz respeito à sua filosofia de trabalho, à missão a que se propõe, às diretrizes pedagógicas que orientam suas ações, à sua estrutura organizacional e às atividades acadêmicas que desenvolve e/ou que pretende desenvolver.

Apesar de obrigatório, o MEC permitiu que a construção do PDI fosse livre, garantindo às instituições o exercício de suas criatividades e liberdades no processo de sua elaboração (BRASIL, 2007). Entretanto, dez eixos temáticos devem estar presentes no documento, por serem tomados como referenciais das análises subsequentes a serem realizadas pelo MEC (BRASIL, 2007), e que contempla os requisitos mínimos estabelecidos no decreto presidencial, sendo:

1 - Perfil institucional;

2 - Projeto pedagógico institucional - PPI;

3 - Cronograma de implantação e desenvolvimento da instituição e dos cursos (presencial e a distância);

4 - Perfil do corpo docente;

5 - Organização administrativa da IES;

6 - Políticas de atendimento aos discentes; 
7 - Infraestrutura;

8 - Avaliação e acompanhamento do desenvolvimento institucional;

9 - Aspectos financeiros e orçamentários; e

10 - Anexos, que deve conter o regimento ou estatuto da IES.

Levantamento realizado por Cardoso (2006) demonstrou que antes de 2002 não existiam planos do gênero, mas a partir de determinado ano, por exigência da legislação, as IES passaram a elaborar o documento.

Muriel (2006, p. 61) apresenta como conceito para o PDI:

[...] como o próprio nome já diz, é um plano, uma programação para que a Instituição de Ensino possa crescer ou fortalecer-se em sua atuação, de acordo com sua missão institucional, objetivos, estratégias e planos de ação que envolve não apenas o setor administrativo, mas também o setor acadêmico. O PDI visa desenvolver a Instituição.

O PDI estipula também, de acordo com Martins (2006, p. 1.010) "[...] a necessidade do estabelecimento de ensino de explicitar a relação entre o seu projeto pedagógico e as finalidades da educação delineadas pelo atual projeto, assim como a demonstração do compromisso social da instituição.”.

Segundo Muriel (2006), ao tornar o PDI obrigatório para o credenciamento de novas IES e a autorização de novos cursos, o governo demonstrou certa preocupação com o planejamento para a implantação de um novo empreendimento ou o crescimento da instituição já existente. Assim, apesar de ser obrigatório por força de lei, é uma oportunidade para as IES realizarem um planejamento que de fato tragam resultados positivos.

Cardoso (2006) explica que de início, as instituições o confeccionavam o PDI apenas para atender os aspectos legais, enquanto que para o MEC era uma forma de instituir maior controle e avaliação da educação superior, pelo crescente número de instituições e cursos. Apenas recentemente que as IES e o MEC passaram a enxergar o PDI como ferramenta de gestão.

\section{PROCEDIMENTOS METODOLÓGICOS}

A pesquisa caracteriza-se como monográfica, também denominada como estudo de caso, consistindo, segundo Cruz e Ribeiro (2003, p. 36) "no estudo de determinados indivíduos, profissões, instituições, condições, grupos ou comunidades, com a finalidade de 
obter generalizações.”. Foram realizadas múltiplos estudos de caso, por analisar oito universidades federais, buscando a ênfase na análise das possíveis contribuições do Plano de Desenvolvimento Institucional e Planejamento Estratégico para a gestão dessas universidades.

As oito universidades analisadas foram:

-Universidade Federal de Alagoas - UFAL;

- Universidade Federal do Amapá - UNIFAP;

- Universidade Federal da Grande Dourados - UFGD;

- Universidade Federal do Maranhão - UFMA;

- Universidade Federal de Minas Gerais - UFMG;

-Universidade de Brasília - UnB;

- Universidade Federal do Pará - UFPA; e

-Universidade Federal de Santa Catarina - UFSC.

A seleção dessas instituições se deu de modo intencional, nas palavras de Creswell (2010), pois não se faz uso de uma forma aleatória de seleção, mas sim a utilização de um critério específico. Nesse sentido, as oito universidades foram selecionadas intencionalmente, por serem objetos de estudo de um projeto de pesquisa aprovado e financiado pela Capes, e conduzido pelos autores.

A pesquisa caracteriza-se como descritiva, em que Cervo, Bervian e Silva (2007, p. 32) entendem haver, por parte do pesquisador, observações, registros e analises dos fatos ou fenômenos sem manipulá-los. Segundo os autores, "[...] é necessário que o resultado da observação seja cuidadosamente registrado, processo que configura a técnica científica da descrição.”. Os registros e análises partiram de dados coletados por meio de entrevistas e análises documentais das oito universidades, objetivando apenas descrever as suas realidades, não havendo intenção de modifica-las a fim de observar outros possíveis resultados.

As entrevistas foram realizadas in loco nas instituições no segundo semestre de 2012, sendo entrevistados vice-reitores, pró-reitores de planejamento, de administração e finanças, e, coordenadores e diretores lotados nessas pró-reitorias. Foi garantido o anonimato dos entrevistados, e portanto, foram designados denominações fictícias nos resultados deste 
artigo. O Quadro 1 apresenta as denominações utilizadas, em ordem aleatórias das universidades.

Além das entrevistas, foram feitas análises documentais dos planos de desenvolvimento institucional e planejamentos estratégicos das universidades, sendo o período da coleta de dados compreendidos no segundo semestre de 2012. As informações que caracterizam as instituições, como número de alunos e docentes, foram coletados em seus respectivos relatórios de gestão, enviados ao Tribunal de Contas da União anualmente. Todos os dados possuem como referência o ano de 2011, pois esses relatórios referem-se ao ano anterior (assim, o relatório de 2012 contém dados de 2011). Também foi consultado a Lei Orçamentária Anual da União para apontar os orçamentos das universidades.

\begin{tabular}{|c|l|}
\hline Denominações das Universidades & Denominações dos entrevistados \\
\hline Alfa & Entrevistado 1 e Entrevistado 2 \\
\hline Beta & Entrevistado 3 \\
\hline Gama & Entrevistado 4 \\
\hline Delta & Entrevistado 5 \\
\hline Zeta & Entrevistado 6 e Entrevistado 7 \\
\hline Sigma & Entrevistado 8 \\
\hline Ômega & Entrevistado 9 \\
\hline
\end{tabular}

Quadro 1 Denominação fictícia e aleatória das universidades pesquisadas Fonte: Elaborado pelos Autores.

Feito a coleta de dados das entrevistas, seguiu-se para as transcrições das mesmas, que é textualizar as falas dos entrevistados. As informações foram reorganizadas a partir do tema e objetivo da pesquisa, e associadas às respostas dos entrevistados, para então proceder interpretações à luz das literaturas utilizadas na fundamentação teórica. $O$ mesmo procedimento foi adotado para as análises documentais.

A interpretação dos dados seguiu a análise interpretativa, que na denominação de Severino (2007, p. 59), parte da compreensão objetiva da mensagem comunicado pelo texto, seguindo para a síntese das ideias do raciocínio e a compreensão profunda do texto. Segundo o autor, a interpretação verifica "[...] como as ideias expostas se relacionam com as posições gerais do pensamento teórico.”. Essa segunda parte da pesquisa foi procedida no primeiro semestre de 2013 . 


\section{RESULTADOS E DISCUSSÕES}

Esta seção apresenta os resultados e discussões da pesquisa sobre as contribuições do PDI e planejamento estratégico para as universidades. Na tabela a seguir, são apresentadas algumas características das instituições estudas, como ano de criação, quantidade de membros e orçamentos.

Tabela 1 Caracterização quantitativa das universidades analisadas - Ano base 2011

\begin{tabular}{cccccc}
\hline Universidade & $\begin{array}{c}\text { Ano de } \\
\text { criação }\end{array}$ & $\begin{array}{c}\text { Alunos } \\
\text { (graduação }+ \\
\text { pós-graduação) }\end{array}$ & Docentes & $\begin{array}{c}\text { Técnico- } \\
\text { administrativos }\end{array}$ & $\begin{array}{c}\text { Orçamento } \\
\text { (milhões R\$) }\end{array}$ \\
\hline UFAL & 1961 & 24.607 & 1.384 & 1.556 & $>447,2$ \\
UFGD & 2005 & 5.334 & 378 & 1.279 & $>95,19$ \\
UFMA & 1966 & 18.464 & 1.374 & 2.194 & $>442,4$ \\
UFMG & 1949 & 35.293 & 2.593 & 4.820 & $>1.140,29$ \\
UFPA & 1957 & 37.931 & 2.634 & 2.304 & $>801,55$ \\
UnB & 1961 & 32.581 & 2.296 & 2.682 & $>1.237,37$ \\
UNIFAP & 1986 & 4.368 & 285 & 214 & $>72,39$ \\
UFSC & 1960 & 35.998 & 1.924 & 3.005 & $>844$ \\
\hline TOTAL & - & $\mathbf{1 9 4 . 5 7 6}$ & $\mathbf{1 2 . 8 6 8}$ & $\mathbf{1 8 . 0 5 4}$ & $\mathbf{5 . 0 8 0 , 3 9}$ \\
\hline
\end{tabular}

Fonte: Relatórios de Gestão das Universidades e MPOG (2013).

Observa-se que há uma discrepância financeira e de pessoal entre as universidades, pois enquanto a UNIFAP possuía em 2011, 499 servidores docentes e técnico-administrativos e orçamento de mais de 72 milhões de reais, a UFMG apresentava 7.413 servidores e orçamento de mais de 1,237 bilhões de reais. A UFGD possui oito anos de existência, enquanto as demais possuem décadas de vivência.

\subsection{CONTRIBUIÇÕES DO PDI E DO PLANEJAMENTO ESTRATÉGICO ÀS GESTÕES DAS UNIVERSIDADES}

As informações processadas evidenciaram que todos os entrevistados relataram benefícios do PDI e do planejamento estratégico para as universidades, seja pela mudança que o processo trouxe à instituição, ou que por ventura possam trazer. Na Universidade Ômega, o entrevistado 9 explica que o os planejamentos auxiliam na gestão ao traçar metas, e assim, visionar a universidade no horizonte, sem pioneirismo. É o mesmo pensamento do entrevistado 7, da Universidade Zeta, que diz sobre as vantagens para a universidade:

Acho que ter um planejamento só trás vantagens. Ela vai conseguir conhecer o terreno onde está pisando, poder projetar o que quer realizar, saber quais 
são os riscos do seu negócio, quais são os desafios que terá que superar. Então, só trás vantagens, quando você tem tudo isso mapeado, planilhado, e apresentado à gestão e à comunidade universitária.

Conhecer a instituição, enxergar-se e o que se quer no futuro, são reflexões que trazem benefícios quando exercitado no PDI e no planejamento estratégico das universidades. Segundo o entrevistado 3, da Universidade Beta

Para organizar uma universidade em processo de implantação, você precisa de um planejamento muito bem feito. O PDI nos deu toda essas informações, do que queríamos, qual era a nossa missão e todo mais. E sobre esse PDI foi construído depois o planejamento estratégico. Até onde a universidade pode chegar, o que a universidade quer ser durante um tempo maior.

O entrevistado 2, da Universidade Alfa, acredita que o PDI e o planejamento estratégico oportuniza “[...] reflexão do que foi feito e proposição do que será." Para o entrevistado 3, da Universidade Beta, os planejamentos oferecem "Um crescimento seguro sem dúvida nenhuma. Sem um PDI e um planejamento estratégico não se consegue construir uma universidade forte." O relato do entrevistado 5 induz que o foi planejado não foi executado, e se o fosse, traria benefícios à Universidade Delta:

O PDI é importante para saber para onde a Universidade vai, não ficar trabalhando sem um documento oficial de planejamento estratégico que aponta para onde vamos. [...] Se realmente fosse implantado, se trabalhássemos realmente nele, a vantagem é totalmente positiva, porque muitas coisas que estão lá, que nós planejamos, que deveriam ter sido executado e não foram, melhoraria a administração da instituição, nós tínhamos concretizado algumas ações que nós deixamos de consultar e verificar o norte da instituição. Ele é vantagem, e principalmente se for trabalhado, e não seja só um instrumento legal.

O entrevistado 8, da Universidade Sigma, diz que os planejamentos oportunizam "Direção, meta, forma de atuação. Metas que antes eram particularizadas agora são institucionais.". A democratização e participação dá lugar a interesses pessoais, pois qualquer ação para ser executada deve ser planejada, e assim, constar em um documento que é construído e disponibilizado ao público. Caso as metas não sejam cumpridas ou não tenham sido previamente incluídas no planejamento, recursos não são liberados. Na Universidade Alfa, o entrevistado 1 alega:

Cada vez mais a comunidade universitária percebe que é necessário o PDI e planejamento estratégico, porque começam a esbarrar naquelas limitações que eu falei antes. Se você vem para cá com um projeto: 'quero fazer um convênio com não sei quem', e a pessoa que vai examinar o projeto diz: 'Olha, isso aqui você tem que mudar aqui por que não está de acordo com o nosso PDI', então ele tomou conhecimento de que existe um PDI e que esse PDI tem que ser levado em conta na 
hora de formular a proposta. Mas eu acho que isso aí é uma coisa muito insipiente da universidade.

Até mesmo afastamento de docentes para cursar pós-graduação deve estar contemplado no planejamento da Universidade Gama, e trazer benefícios para o curso do professor, que deve aguardar uma fila de espera. Caso contrário, a instituição não autoriza sua formação:

\begin{abstract}
Então o professor tem que enxergar isso lá no plano dele, no plano da unidade acadêmica, porque se a unidade acadêmica cria um planejamento estratégico, solicita para ele que ele faça um plano, que a gente chama aqui de PAA, plano de atividades acadêmicas. Aí o professor olhando o projeto do curso e olhando o da unidade acadêmica, ele faz para três anos o plano de atividades acadêmicas dele, então ele não pode simplesmente dizer assim: eu quero fazer, eu sou mestre, eu quero fazer doutorado. Sim, você vai fazer doutorado por que? Estava no seu plano? Se não estiver no plano de atividades acadêmicas dele, que ele quer fazer o doutorado em dois anos, ele não consegue sair furando a fila, porque tem todo o resto do pessoal que colocou no seu plano isso, e a gente mensura, junta projeto e a possibilidade da saída desse professor ou não. Essa área que ele está indo é para quê? Reforça o curso ou é uma coisa que ele quer fazer mais do desejo individual dele? [...] A Pró-Reitoria de Graduação também olha muito para ver, por exemplo, se essas saídas, elas estão potencializando áreas de concentração do curso ou fragilidades do curso, porque aí a gente pega a prova do ENADE, vê onde o nosso aluno é mais frágil. Normalmente é uma área de estudo, aquela área de estudo tem haver com os professores estão ali lotados, aí às vezes tem pouco, ou então o cara só tem mestrado ou especialização.
\end{abstract}

O PDI e o planejamento estratégico também servem para mostrar à gestão que a realidade mudou, e que é preciso rever metas, como é o caso da Universidade Beta. O entrevistado 3 alegou:

Algumas questões que própria comunidade enxerga, às vezes vai se mudando com o tempo, e você percebe: 'olha, o anseio da comunidade não é mais aquele que foi planejado há alguns anos, então há uma necessidade de replanejamento'.

O PDI e o planejamento estratégico oportunizaram o redesenho dos processos internos na Universidade Ômega, acarretando que algumas tramitações desnecessárias apareceram e foram consideradas morosas, por apenas depender de uma assinatura. Assim, ficou evidenciado que determinado pró-reitor ou diretor não precisaria assinar ou despachar determinados processos. O planejamento acabou por mapear a instituição, e assim, a administração sabe o que faz, mostrando o que está sobrando ou faltando. O entrevistado afirmou que essa realidade tornou-se um perigo para certos gestores, pois tornou o cargo dos mesmos duvidosos, sobre qual é a sua finalidade. Na Universidade Gama, ao mapear a hierarquia durante o processo de planejamento, houve a eliminação de um cargo antes considerado importante na instituição, o de chefe de departamento: 
A gente acabou com o chefe de departamento. A gente colocou o colegiado direto com o chefe de centro, sem chefe de departamento. A gente tirou um nível de meio, para empoderar mais os colegiados, para dar mais poder aos colegiados. O chefe de departamento estava, por oras essa coisa de hierarquia, ela pode funcionar como uma faca de dois gumes, então a gente estava percebendo que o chefe de departamento, ele é só uma figura administrativa, que estava às vezes exercendo um poder político em cima das coisas e as grandes questões sérias não estava acontecendo. Então a gente resolveu eliminar. Ficou o diretor, o diretor normalmente tem um leque de cursos ali, e ele dá autonomia para esses curso fazerem, desde que esteja alinhado com o PPI da instituição, e aí com as diretrizes curriculares nacional.

A descontinuidade administrativa é considerada um fator negativo para as instituições, em especial aquelas que possuem cargos eletivos, cujo dirigente principal é eleito politicamente. Sendo um processo participativo, o PDI e o planejamento estratégico contribuem para que não ocorra essa descontinuidade quando há troca de reitores. De acordo com o entrevistado 8, da Universidade Sigma, essa é uma das principais vantagens do planejamento:

[...] deixando também um planejamento para a gestão seguinte para que não haja um descompasso, uma quebra de ligação, uma interrupção entre a gestão atual e a que está por vir, pois o que se vê hoje em dia é que quando alguém que assume o lugar de reitor por exemplo, troca basicamente tudo da gestão passada, não dá continuidade alguma à gestão anterior, mesmo as coisas que deram certo anteriormente, não dá continuidade. O PDI passa a ser institucional, o planejamento da instituição e não mais do gestor, e isso passa a ser mais fundamental, não de um professor A, ou professor B.

Outra contribuição relatada por dois entrevistados foi a noção de competitividade externa, resumida em a universidade ser a melhor em determinados aspectos. Assim, o PDI e o planejamento estratégico da Universidade Ômega tem essa característica, em querer torná-la reconhecida nacional e internacionalmente, em especial, ser a melhor e referência na região brasileira em que se insere. Na Universidade Gama, a visão e a prática competitiva são expressivas. O entrevistado 4 entende que a instituição quer ser internacional e referência nacional, e elenca algumas ações que a levam a alcançar esse objetivo:

\footnotetext{
Queremos ser uma universidade internacional. Internacionalizar a graduação e pósgraduação. E isso está muito mais no eixo sul e sudeste, precisa intensificar essa nossa participação nesse processo de internacionalização das universidades. Então esse é um objetivo estratégico que a gente tem seguido fielmente, a unhas e dentes, brigando por isso. Então nós vamos para essa competitividade no ambiente externo, queremos ser a referência. Temos crescido muito nas comissões nacionais. A Universidade Gama colocou no objetivo que tinha que estar presente em todas as comissões nacionais que falassem da educação superior. Hoje nós praticamente temos assento em quase todas elas. Inclusive teve uma meta que colocamos que deveríamos ser coordenador desses, tem o COGRAD, o FORGRAD, o FORPLAD,
} 
queríamos ter duas ou três coordenações desses. Chegamos a ter duas presidências, professores aqui presidindo esses fóruns nacionais em dois dele, dos cinco melhores e maiores na área de educação superior pública, e tínhamos praticamente assim, mais dois coordenadores regionais, que faziam parte da cúpula local. Temos metas ambiciosas assim, porque a Universidade Gama quer se projetar para ser reconhecida nacionalmente. E hoje a Universidade Gama já tem um certo reconhecimento da comunidade nacional.

Pelo exposto, a Universidade Gama não apenas estipula como meta e visão, ser a melhor em algo, mas delimita ações práticas para se chegar ao objetivo, tendo conquistado cada vez mais espaços na esfera nacional.

Pelas entrevistas apresentadas, observa-se que o PDI e o planejamento estratégico trazem contribuições à gestão das universidades que a praticam.

\section{CONCLUSÃO}

Esta pesquisa apresentou as contribuições do Planejamento Estratégico e do Plano de Desenvolvimento Institucional na gestão de universidades federais brasileiras, demandando esforços para a coleta de dados em oito universidades federais brasileiras, sendo as Universidades Federais de Alagoas, da Grande Dourados, do Maranhão, de Minas Gerais, do Pará, de Brasília, do Amapá e de Santa Catarina. Observou-se diferenças entre uma universidade e outra, em termos de orçamento, período de existência e quantitativo de membros da comunidade universitária.

O PDI é um planejamento obrigatório por exigência legal, instituído pelo Sistema Nacional de Avaliação da Educação Superior - SINAES para que as instituições de educação superior o elaborem e submetam ao MEC para avaliação. Para ser considerado PDI, o documento não precisa, obrigatoriamente, seguir um modelo fixo, pois como explica Cardoso (2006), por parte do Ministério, buscou-se deixar a confecção do plano flexível, oportunizando criatividade e inovação por parte da instituição. Entretanto, o MEC criou um modelo para que as IES tivessem uma referência a seguir, contendo dez eixos temáticos.

Ficou evidente que o Plano de Desenvolvimento Institucional e o Planejamento Estratégico trazem, na visão dos gestores das universidades pesquisadas, benefícios às instituições, principalmente por oportunizarem o auto conhecimento. Os planejamentos fazem com que a gestão enxergue a instituição dentro de um horizonte, e para isso, acaba traçando metas, objetivos e ações estratégicas, propiciando um rumo às universidades, que não ficam às cegas. Quando os gestores conhecem o terreno em que se situam, trabalham de maneira a 
modificar as estruturas e as ações do dia a dia, oportunizando eficácia e eficiência para a gestão das universidades.

Dessa forma, amparado nas análises documentais e entrevistas, é possível afirmar que o PDI e o planejamento estratégico podem contribuir para a gestão das universidades federais brasileiras.

\section{REFERÊNCIAS}

ALMEIDA, Martinho Isnard Ribeiro de. Manual de planejamento estratégico: desenvolvimento de um plano estratégico com a utilização de planilhas Excel. 3. ed. São Paulo: Atlas, 2010.

AMARAL, Nelson Cardoso. Financiamento da educação superior: Estado x Mercado. Piracicaba: Editora UNIMEP, 2003.

BRASIL. Lei $\mathrm{n}^{\circ}$ 9.394, de 20 de dezembro de 1996. Estabelece as diretrizes e bases da educação nacional. Diário Oficial da República Federativa do Brasil, Poder Executivo, Brasília, DF, nº 248, 23 dez. 1996. Seção 1, p. 27.834.

BRASIL. Lei n ${ }^{\circ} 10.861$, de 14 de abril de 2004. Institui o Sistema Nacional de Avaliação da Educação Superior - SINAES e dá outras providências. Diário Oficial da União, Poder Executivo, Brasília, DF, no 72, 15 abr. 2004. Seção 1, p. 03.

BRASIL. Ministério da Educação. Instruções para elaboração de Plano de Desenvolvimento Institucional. Brasília, DF, 2007. Disponível em:

$<$ http://www2.mec.gov.br/sapiens/pdi.html > . Acesso em: 28 ago. 2012.

CARDOSO, Wille Muriel. O impacto do plano de desenvolvimento institucional na profissionalização das instituições privadas de ensino superior. $66 \mathrm{f}$. Dissertação (Mestrado em Administração) - Centro de Pós-Graduação em Administração das Faculdades Integradas de Pedro Leopoldo, da Fundação Cultural Dr. Pedro Leopoldo, Pedro Leopoldo, 2006.

CERVO, Amado Luiz; BERVIAN, Pedro Alcino; SILVA, Roberto da. Metodologia científica. 6. ed. São Paulo: Pearson Prentice Hall, 2007.

COSTA, Eliezer Arantes da. Gestão estratégica: construindo o futuro de sua empresaFácil. São Paulo: Saraiva, 2012.

CRESWELL, John W. Projeto de pesquisa: métodos qualitativo, quantitativo e misto. Tradução por Magda Lopes. Consultoria, supervisão e revisão técnica por Dirceu da Silva. 3. ed. Porto Alegre: Artmed, 2010.

CRUZ, Carla; RIBEIRO, Uirá. Metodologia científica: teoria e prática. Rio de Janeiro: Axcel Books, 2003. 
MACHADO, Luís Eduardo. Gestão estratégica para instituições de ensino superior privadas. Rio de Janeiro: Editora FGV, 2008.

MARTINS, Carlos Benedito. Uma reforma necessária. Educação e Sociedade, Campinas, v. 27, n. 96 - Especial, p. 1001-1020, out. 2006.

MAXIMIANO, Antonio Cesar Amaru. Teoria geral da administração. 1. ed. 11. reimpr. São Paulo: Atlas, 2012.

MPOG, Ministério do Planejamento, Orçamento e Gestão. Projeto de lei orçamentária exercício financeiro 2013. volume V. Brasília, DF: Secretaria de Orçamento Federal, 2012. Acesso em: 28 jan. 2013. Disponível em:

$<$ http://www.planejamento.gov.br/secretarias/upload/Arquivos/sof/ploa2013/Volume_5.pdf $>$

MURIEL, Roberta. Plano de desenvolvimento institucional - PDI: análise do processo de implantação. Brasil: Editora Hoper, 2006.

OLIVEIRA, Djalma de Pinho Rebouças de. Planejamento estratégico: conceitos, metodologias e práticas. 25. ed. São Paulo: Atlas, 2008.

PEREIRA, Maurício Fernandes. Planejamento estratégico: teorias, modelos e processos. São Paulo: Atlas, 2010.

SEVERINO, Antônio Joaquim. Metodologia do trabalho científico. 23. ed. ver. atual. São Paulo: Cortez, 2007.

SILVA, Júlio Eduardo Ornelas et al. A pós-graduação e o desenvolvimento sócio-econômico: análise da gestão pública para a educação por meio dos orçamentos públicos federais. Revista do CCEI, v. 15, n. 28, p. 132-152, ago. 2011.

UFAL, Universidade Federal de Alagoas. Plano de Desenvolvimento Institucional 2008-2012. Maceió: UFAL, 2008. Acesso em: 17 out. 2012. Disponível em:

$<$ http://www.ufal.edu.br/transparencia/relatorios/planejamentos/plano-de-desenvolvimentoinstitucional/PDI_2008_2012.pdf $>$.

UFAL, Universidade Federal de Alagoas. Relatório de gestão do exercício de 2011. Maceió: UFAL, 2012. Acesso em: 17 out. 20058. Disponível em:

$<$ https://contas.tcu.gov.br/econtrole/ObterDocumentoSisdoc? $\operatorname{codArqCatalogado}=4372342 \&$ se AbrirDocNoBrowser $=1>$.

UFGD, Universidade Federal da Grande Dourados. Plano de Desenvolvimento Institucional 2008-2012. Dourados: UFGD, 2008. Acesso em: 17 out. 2012. Disponível em:

$<$ http://www.ufgd.edu.br/reitoria/pdi-ufgd $>$.

UFGD, Universidade Federal da Grande Dourados. Relatório de gestão do exercício de 2011. Dourados: UFGD, 2012. Acesso em: 17 out. 2012. Disponível em:

$<$ https://contas.tcu.gov.br/econtrole/ObterDocumentoSisdoc? codArqCatalogado $=4355371 \&$ se AbrirDocNoBrowser $=1 .>$ 
UFMA, Universidade Federal do Maranhão. Plano de Desenvolvimento Institucional 20122016. São Luís: UFMA, 2012a. Acesso em: 19 out. 2012. Disponível em: $<$ http://www.ufma.br/arquivos/pdi ufma $18 \quad 10$ 2012.pdf $>$.

UFMA, Universidade Federal do Maranhão. Relatório de gestão do exercício 2011. São Luís: UFMA, 2012b. Acesso em: 17 out. 2012. Disponível em:

$<$ https://contas.tcu.gov.br/econtrole/ObterDocumentoSisdoc? $\operatorname{codArqCatalogado}=4355931 \&$ se $\underline{\text { AbrirDocNoBrowser }=1>\text {. }}$

UFMG, Universidade Federal de Minas Gerais. Plano de Desenvolvimento Institucional 2008-2012. Belo Horizonte: UFMG, 2008. Acesso em: 17 out. 2012. Disponível em: $<$ https://www.ufmg.br/conheca/pdi_ufmg.pdf $>$.

UFMG, Universidade Federal de Minas Gerais. Relatório de gestão do exercício de 2011. Belo Horizonte: UFMG, 2012. Acesso em: 17 out. 2012. Disponível em:

$<$ https://contas.tcu.gov.br/econtrole/ObterDocumentoSisdoc? $\operatorname{codArqCatalogado}=4357523 \&$ se $\underline{\text { AbrirDocNoBrowser }=1>}$.

UFPA, Universidade Federal do Pará. Plano de Desenvolvimento Institucional 2011-2015. Belém: UFPA, 2011. Acesso em: 17 out. 2012. Disponível em:

$<$ http://www.portal.ufpa.br/docs/pdi aprovado_final.pdf $>$.

UFPA, Universidade Federal do Pará. Relatório de gestão do exercício de 2011. Belém: UFPA, 2012. Acesso em: 17 out. 2012. Disponível em:

$<$ https://contas.tcu.gov.br/econtrole/ObterDocumentoSisdoc?codArqCatalogado $=4328193 \&$ se AbrirDocNoBrowser $=1>$.

UFSC, Universidade Federal de Santa Catarina. Plano de Desenvolvimento Institucional 2010-2014. Florianópolis: UFSC, 2010. Acesso em: 17 out. 2012. Disponível em:

$<$ http://pdi.paginas.ufsc.br/files/2011/03/PDI-2010-2014.pdf $>$.

UFSC, Universidade Federal de Santa Catarina. Relatório de gestão 2011. Florianópolis: UFSC, 2012. Acesso em: 17 out. 2012. Disponível em:

$<$ https://contas.tcu.gov.br/econtrole/ObterDocumentoSisdoc? codArqCatalogado $=4302702 \&$ se

AbrirDocNoBrowser $=1>$.

UNB, Universidade de Brasília. Bases do planejamento estratégico 2011 a 2015. Brasília: UnB, 2011. Acesso em: 17 out. 2012. Disponível em:

$<$ http://www.dpo.unb.br/documentos/Bases_2011-2015 preliminar.pdf $>$.

UNB, Universidade de Brasília. Relação de documentos de planejamento da UnB. Brasília: UnB, 2013. Acesso em: 07 fev. 2013. Disponível em: < $\underline{\text { http://www.dpo.unb.br/pdi.php>. }}$

UNB, Universidade de Brasília. Relatório de gestão do exercício de 2011. Brasília: UnB, 2012. Acesso em: 17 out. 2012. Disponível em:

$<$ https://contas.tcu.gov.br/econtrole/ObterDocumentoSisdoc? codArqCatalogado $=4358204 \&$ se AbrirDocNoBrowser $=1>$. 
UNIFAP, Universidade Federal do Amapá. Plano de Desenvolvimento Institucional 20102014. Macapá: UNIFAP, 2010. Acesso em: 17 out. 2012. Disponível em: $<$ http://www2.unifap.br/pdi/files/2010/05/pdi-2010-2014.pdf $>$.

UNIFAP, Universidade Federal do Amapá. Relatório de gestão do exercício de 2011. Macapá: UNIFAP, 2012. Acesso em: 17 out. 2012. Disponível em:

$<$ https://contas.tcu.gov.br/econtrole/ObterDocumentoSisdoc? $\operatorname{codArqCatalogado}=4357237 \&$ se AbrirDocNoBrowser $=1>$. 